\section{俩 Heighten Science P U B L I C I T T I O N S Corporation ISSN 2573-7716}

\title{
The transnasal bilobed flap for medial canthal reconstruction
}

\author{
Corredor-Osorio Rafael*, Massaro-Corredor Martha Gabriela \\ and Buitrago-Corredor Vanessa Gabriela \\ Oculoplastic and Orbit Service, Eye Center Specialized Ophthalmology Corredor, Valera \\ (Trujillo) Venezuela
}

\begin{abstract}
*Address for Correspondence: Rafael CorredorOsorio, Eye Center Specialized Ophthalmology Corredor. Av. Bolívar, CC Acacias local 31, Valera (Trujillo) Venezuela, Tel: 58- 271- 2310571; Email: raficorredor@yahoo.com
\end{abstract}

Submitted: 25 October 2017

Approved: 03 November 2017

Published: 06 November 2017

Copyright: @ 2017 Rafael CO, et al. This is an open access article distributed under the Creative Commons Attribution License, which permits unrestricted use, distribution, and reproduction in any medium, provided the original work is properly cited.

\section{Abstract}

Reconstruction of the eyelids, especially medial canthal area, is one of the greatest challenges faced by the oculoplastic, head and neck surgeons. A patient with a medial canthal defect, following oncological resection involving the medial canthus, upper and lower eyelids, and nose is presented. The defect was reconstructed using a transnasal bilobed flap. The transnasal bilobed flap is a simple and effective for medial canthal reconstruction and provides in one-time reconstruction and preserves the local anatomy.

\section{Introduction}

The medial canthal region is a common site for tumors, particularly basal cell carcinoma (BCC) [1]. BCC accounts for $70-80 \%$ of all cutaneous malignancies in the head face and neck region [2]. The medial canthal region represents a multicontoured area with great variation in skin thickness, color, texture, and appendage density, and it includes contributions from the orbital and tarsal portions of the upper and lower eyelids, the nasal sidewall, the glabella [3,4], brow, cheek [4,5], the bony attachments of the medial canthal tendon, the lacrimal puncta, and arteriovenous and neural bundles that supply and innervate the region [4-6]. Existing therapeutic strategies include direct suture, free skin grafts and skin flaps [7]. The surgical medial canthus is much larger than the anatomical medial canthus, and extends vertically into the sub-brow region, medially to the side of the nose and close to the midline, and inferiorly onto the cheek $[4,5]$. We describe the usefulness of the transnasal bilobed flap for medial canthal sreconstruction, and highlight some key features, which are illustrated in this case.

\section{Case Report}

A 49-yeard old woman presented to us with a complaint of an asymptomatic ulcer located in right medial canthus, the lower lid and the adjoining nasal region for 2 years duration which was slow growing in nature (Figure 1). The $2 \times 3 \mathrm{~cm}$ ulcer was of insidious onset and gradually increased in size; it was not well demarcated and had a black pigmented crusted surface. Her visual acuity and eyelid movements were normal.

\section{Surgical technique}

The flap is made from the dorsum and contralateral aspect of the nose, taken across horizontally oriented relaxed skin tension lines [8]. The two lobes of the skin flap are then planned and outlined adjacent to the lesion. The angle between the two lobes can be varied from $30^{\circ}$ to $120^{\circ}$, to take advantage of areas with lax skin and to ensure closure of incisions along relaxed skin tension lines [9]. The first or primary lobe diameter must be similar to the vertical length of the defect. The secondary lobe or distal is half 
the size of the primary and is slid into defect created by rotating the primary lobe. The axis of rotation is closer to the first that the second lobe, thus introducing an element of advancement to the rotation. The skin and subcutaneous tissue on the dorsum of the nose are undermined widely, and a radial reliving incision may be made at the distal end of the secondary lobe to aid rotation [8].

A suitable bilobed flap is marked on the skin (Figure 2A) before the subcutaneous injection of bupivacaine $05 \%$ with 1:200.000 epinephrine and then apply firm pressure for 5 minutes. The lesion is then excised with $3 \mathrm{~mm}$ security margins and sent for pathology to verify clear margins (Figure 2B). The flap boundaries are cut, dissected and mobilized with blunt scissors beneath the flap and across the dorsum of the nose. The primary lobe is then elevated, rotated and positioned in the defect to confirm that the size of the flap approximates of the defect. Three deep invert Vicryl (polyglactin 910; Ethicon) sutures are placed to position the flap with minimal tension (Figure 2C). While, 7/0 Prolene (polypropylene; Ethicon) sutures are placed to close the epidermis in simple fashion (Figure 2D,2E). A bolster is applied over flap to push the skin gently against the recipient bed. The sutures are removed in 10 days and topical ointment is applied twice daily.Histological examination revealed un BCC with a separate focus of infiltrative tumor, confirmed that the margin was free of tumor. The patient has been followed up for 1 year with no evidence of recurrence and has no concerns with eyelid function, visual field and epiphora (Figure 3).
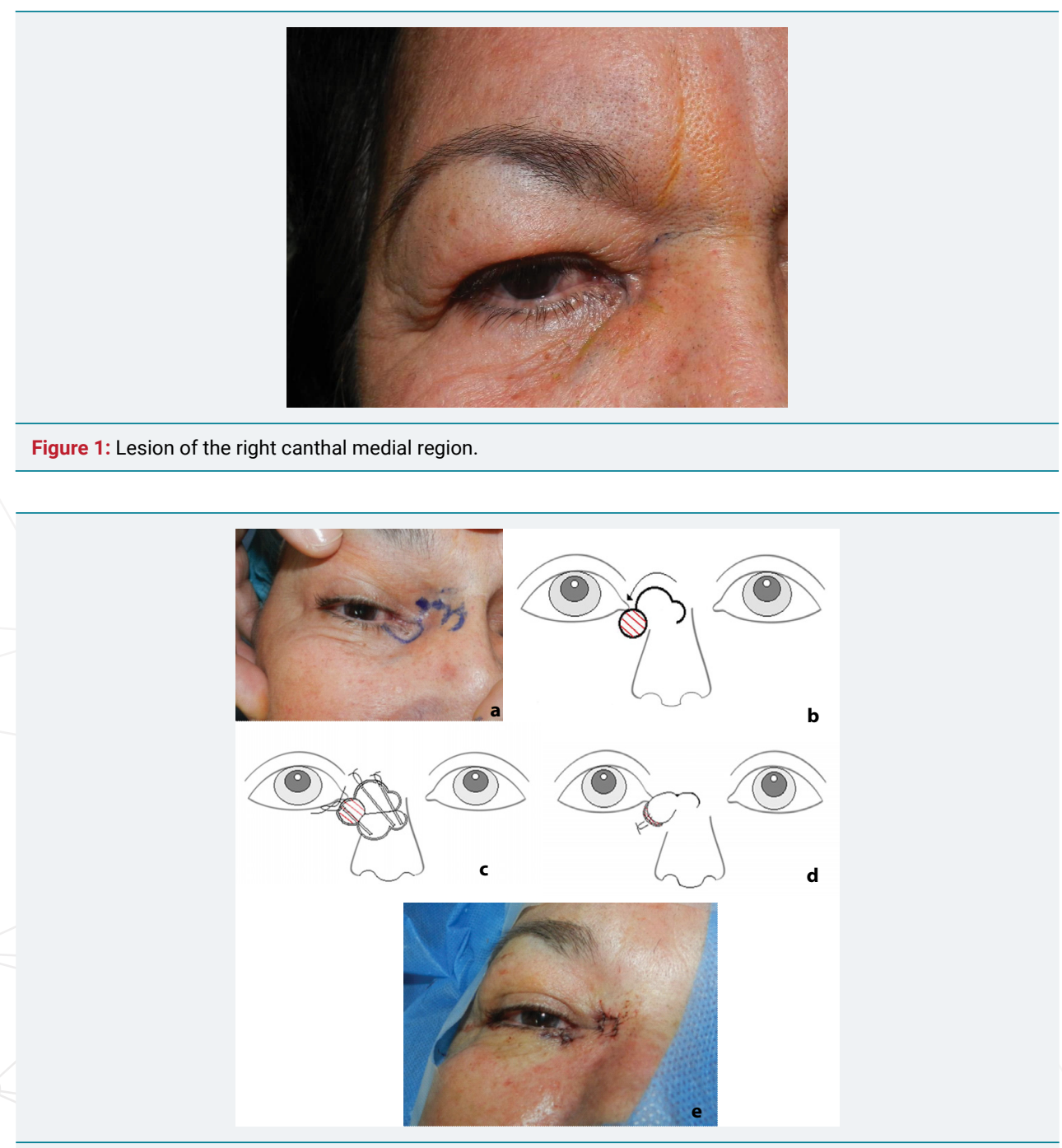

Figure 2: A: Preoperative view of the lesion and flap design. B: Defect after resection. C: Dissection of Flaps (three deep invert Vicryl sutures are placed to position the flap with minimal tension). D: Direct closure of the wounds. E: Immediate postoperative view. 


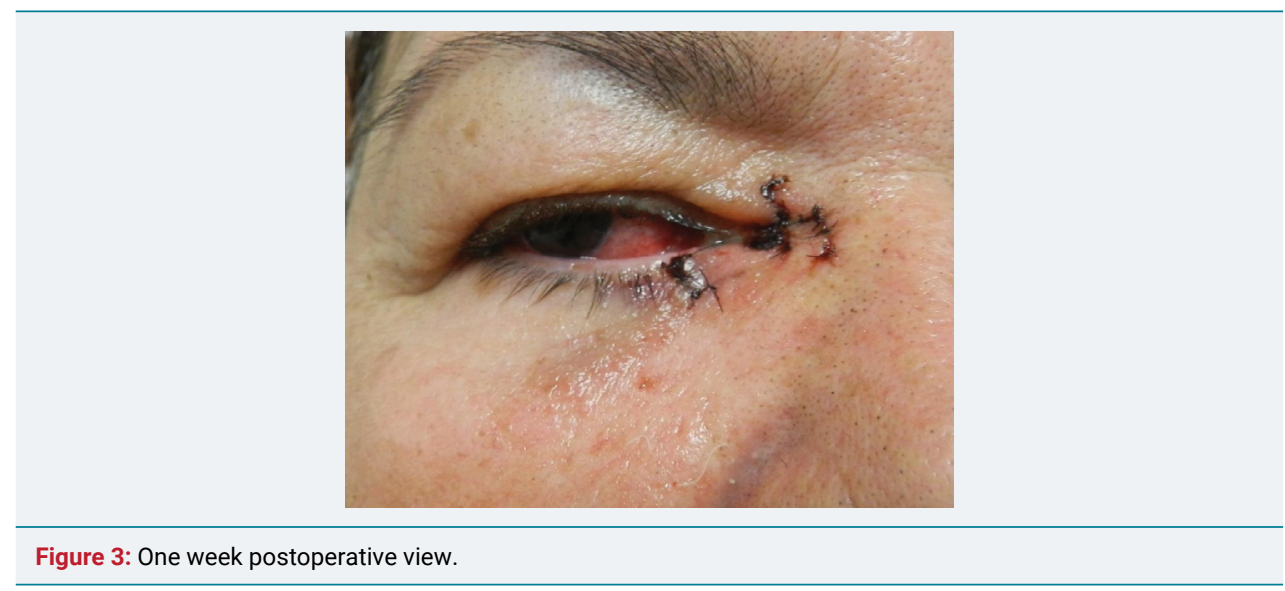

\section{Discussion}

Esser in 1918 first described and used the bilobed flap to repair nasal tip cutaneous defects [10-11]. Reconstruction of the medial canthus defects is an oculoplastic challenge to attain the optimal surgical and cosmetic results. Briefly, an ideal procedure does no exist; therefore, a variety of different surgical procedures is in use, each of which has its advantages and disadvantages [7]. An ideal rotation flap involves skin of the same epidermal characteristics as the medial canthal area [8]. The dorsum of the nose has this advantage, and techniques using V-Y advancement flaps, rhomboid flaps or rotational transnasal advancement flaps are described $[4,8]$. The bilobed flap is commonly used rotational flap for plastic reconstruction especially in situations with tight skin, e.g., dorsum of the nose, sole of the foot [8]. Its oculoplastic use has been limited to reconstruction of anterior lamella defects of the lower eyelid and medial canthal like our case.

The bilobed flap originally consisted of a flap of 2 lobes of the same size, angled at $90^{\circ}$ and $180^{\circ}$ to the site of the defect. Then, the bilobed flap was classified into 2 types: type 1 with a center of rotational in the second lobe, primarily a rotational flap, and, type 2 with the center of rotational between the 2 lobes, making it both a rotational and advancement flap [8]. In our case the bilobed flap was type 2, consisting of skin and subcutaneous rotated into adjacent defect, with a large primary lobe and smaller secondary lobe. By using the infraglabellar region for the second lobe, the thickness of the skin of the secondary defect will be uniform because the tissue would rotate from skin with similar thickness. The healing of the scar from the transnasal secondary lobe follows the natural lines of the nasal bridges [8]. In our case, the second flap was only half diameter of the primary flap to achieve adequate closure of the defect. Bilobed flap may be used to reconstruct mayor defects in different anatomical regions.

Due to the high flexibility and freedom of movement of the lobes, the bilobed design has been demonstrated to be versatile, reliable technically practical in microsurgery [11] and provides good cosmesis.

\section{Conclusion}

In summary, we presented a case report demonstrating the application of the bilobed flap in the medial canthal reconstruction. This is a surgical technique which can be performed with ease under local anesthesia and hence avoid post-surgical complications such as ectropion and dog ear deformities. In the bilobed flap, the incision of the secondary lobe should be avoided until the primary lobe is elevated and undermining the tissue of the defect primary to avoid complications. A benefit of this flap for medial canthal reconstruction is that provides superb color, tissue thickness and texture match.as the original defect and does not require of a second surgical procedure. Other of the advantages of the technique described in this paper 
are related to the use of the skin taken from the second lobe from the infraglabellar transnasal because it follows the natural lines of the nasal bridge reason why it doesn't left visible scars on the glabellar region. The tension is reduced thus improving the quality of the scar and decreasing the possibility of relapse. The bilobed flap has its own blood supply; therefore, there is a faster healing and a low risk of necrosis and infection. One of the disadvantages is due to his localization on the lower eyelid can generate ectropion, in this case the surgeon can decide which flap or combination of flaps is appropriated either the cheek advancement or the lower eyelid advancement flap. The bilobed flap technique is useful to physicians as otolaryngology, plastic surgery, surgical dermatology and head and neck surgeons excising superficial skin cancers followed by anatomical reconstruction.

\section{Informed consent}

Written informed consent was obtained from the patient for the publication of this case report and accompanying images.

\section{References}

1. Berry MG, Fernandes AEL. Triple-flap medial canthal reconstruction. Can J Plast Surg. 2008; 16: 170172. Ref.: https://goo.gl/Bx4q3H

2. Kannan R, John R. Reconstruction of ala of nose with bilobed flap: a 2 year follow-up. J Maxillofac Oral Surg. 2011; 10: 57-59. Ref.: https://goo.gl/gLD4Ry

3. Perry JD, Taban M. Superiorly based bilobed flap for inferior medial canthal and nasojugal fold defect reconstruction. Ophthalmic Plastic Reconstruc Surg. 2009; 25: 276-279. Ref.: https://goo.gl/uyNrk6

4. Corredor-Osorio R. Rhomboid flap: An option to medial canthal reconstruction. Our Dermatol Online. 2017; 8: 329-332. Ref.: https://goo.gl/tMkARn

5. Maloof AJ, Leatherbarrow B. The glabellar flap dissected. Eye. 2000; 14: 597-605. Ref.: https://goo.gl/7r73kq

6. Behroozan DS, Goldberg LH. Upper eyelid rotation flap for reconstruction of medial canthal defects. J Am Acad Dermatol. 2005; 53: 635-638. Ref.: https://goo.gl/9wC98A

7. Bertelmann E, Rieck P, Guthoff R. Medial canthal reconstruction by a modified glabellar flap. Ophthalmologica. 2006; 220: 368-371. Ref.: https://goo.gl/YnHLMD

8. Metha JS, Olver JM. Infraglabellar transnasal bilobed flap in the reconstruction of medial canthal defects. Arch Ophthalmol. 2006; 124: 111-115. Ref.: https://goo.gl/19Tojp

9. Sharma V, Benger R, Martin P. Techniques of periocular reconstruction. Indian J Ophthalmol. 2006; 54: 149-158. Ref.: https://goo.gl/iewPzD

10. White $\mathrm{CP}$, Rosen N, Muhn CY. The usefulness of the bilobed flap for lateral cheek defects. Can $\mathrm{J}$ Plast Surg. 2012; 20: e19-e21. Ref.: https://goo.gl/eYB9ip

11. Kelahmetoglu O, Yagmur C, Aslan O, Firinciogullari R. The bilobed flap popliteal defect reconstruction. Cas Rep Plast Surg Hand Surg. 2014; 1: 8-10. Ref.: https://goo.gl/LZ7b86 